\title{
Hans Jonas e a proposta de uma ética \\ para a civilização tecnológica
}

\section{Hans Jonas and the proposal for an ethics for the technological civilization}

\author{
Mario Sergio ALENCASTRO*
}

\begin{abstract}
RESUMO
A crise ambiental contemporânea é o cenário a partir do qual se desenvolve o presente artigo. As sociedades modernas estão diante de um grande paradoxo, pois, ao mesmo tempo em que a tecnologia se faz cada vez mais presente na vida das pessoas, as suas consequências, muitas vezes imprevisíveis e perigosas para o ser humano e meio ambiente, estão impondo novas reflexões axiológicas. Nesse contexto, o objetivo principal do trabalho é discutir a possibilidade da formulação de uma ética de responsabilidade, em face da crise ambiental da civilização técnico-científica. Para tanto, tomou-se como referência a teoria ética proposta por Hans Jonas, autor emblemático no campo do ambientalismo e cuja contribuição teórica parece mais pertinente às questões que serão abordadas.
\end{abstract}

Palavras-chave: ética; meio ambiente; responsabilidade.

\begin{abstract}
The contemporary environmental crisis is the framework for this paper. Modern societies face a great paradox: as technology is becoming ever present in modern life; its frequently unexpected and even dangerous consequences for human beings and the environment call for new ethical reflections. In this context, the purpose of this paper is to discuss the possibility of formulating an ethics of responsibility towards the environmental crisis of the technical-scientific civilization. To this end, the ethics proposed by Hans Jonas, an emblematic author in the environmentalism field, whose theoretical contributions seem to be very pertinent to the issues addressed here.
\end{abstract}

Key-words: ethics; environment; responsibility.

\section{Introdução}

O presente artigo é resultado da tese de doutoramento do autor e reproduz algumas reflexões desenvolvidas naquele trabalho. Tem por objetivo principal chamar a atenção sobre a obra de Hans Jonas, filósofo que apresentou uma sistemática tentativa de fundamentar uma ética para a civilização tecnológica, com fortes reflexos na questão

" Professor na Universidade Tuiuti e nas Faculdades Integradas Santa Cruz, Curitiba/PR. E-mail: contato@alencastro.pro.br. 
ambiental, e que tem servido de inspiração para as mais diversas discussões sobre o tema ${ }^{1}$.

Defende-se novamente aqui a ideia de que a atual crise ambiental que assola a humanidade é fruto de uma lógica de ação - um ethos ${ }^{2}$ - que tem caracterizado as modernas sociedades industriais capitalistas, que veem o ambiente natural apenas como fonte de matéria-prima para a produção de mercadorias, e a natureza como algo aberto e disponível para todo tipo de manipulação e exploração técnico-científica com fins econômicos.

Partindo-se do pressuposto de que a ética auxilia as sociedades a buscar o que é bom e desejável para todos, emerge a questão: por que ainda há esse impasse no que diz respeito à construção de uma ética de responsabilidade e cuidado para com o meio ambiente? Ou, como quis Karl-Otto Apel (1994, p.172), "uma ética de responsabilidade solidária em face da crise ecológica da civilização técnico-científica", que possibilite a orientação ético-política fundamental para uma era marcada pelo agravamento da crise ambiental e que leva em consideração a sustentabilidade planetária e a responsabilidade para com as gerações futuras.

Hans Jonas tentou resolver essa questão quando propôs uma ética de responsabilidade para com as gerações futuras e que nortearia o agir humano com vistas à sobrevivência planetária. Para ele, em face das terríveis intervenções do homem sobre a natureza, atitudes urgentes seriam necessárias. As gerações futuras não podem ser ignoradas e tampouco a qualidade do meio ambiente. Sendo assim, seu projeto de uma ética para a civilização tecnológica pode representar uma alternativa importante e necessária para a crise ambiental, o que justifica uma análise criteriosa.

\section{Hans Jonas e o ensaio de uma ética para a civilização tecnológica}

Hans Jonas nasceu em 1903, na cidade de Mönchengladbach (Alemanha), e morreu em 1993, em Nova York. Foi discípulo de Husserl e Heidegger. Emigrou para Israel em 1933, depois para o Canadá (1949) e, posteriormente, para os Estados Unidos (1955). Na década de 1970, interessou-se pelos problemas éticos que poderiam surgir a partir dos avanços da tecnologia, e em 1979 foi publicada sua principal obra, $O$ Princípio Responsabilidade: ensaio de uma ética para a civilização tecnológica (Das Prinzip Verantwortung: Versuch einer Ethic für die Technologische Zivilisation).

Nessa obra, Jonas antevê, no choque causado pelas bombas atômicas de Hiroshima e Nagasaki, o marco inicial do abuso do domínio do homem sobre a natureza, causando sua destruição. A evolução de uma tecnologia com grande potencial destruidor e devastador como essa, estaria interpelando a estruturação de uma nova ética, capaz de impor limites à evolução tecnológica acelerada e descontrolada. Jonas, mais do que a consciência de um apocalipse brusco, teria percebido também a possibilidade de um apocalipse gradual decorrente do perigo crescente dos riscos do progresso técnico global e seu uso inadequado. Trata-se do mesmo perfil de risco que Ulrich Beck identificou como inerente às sociedades contemporâneas, mas que Hans Jonas abordou de forma radical e decisiva ${ }^{3}$.

Nas primeiras linhas do prólogo do Princípio Responsabilidade, Hans Jonas alerta para o fato de que a ciência e a técnica atuais, impulsionadas incessantemente pela atividade econômica, estão pondo em movimento forças nunca antes conhecidas, cujos efeitos destrutivos,

\footnotetext{
${ }^{1}$ Trata-se do trabalho intitulado A ética de Hans Jonas: alcances e limites sob uma perspectiva pluralista, apresentado junto ao Programa de Doutorado em Meio Ambiente e Desenvolvimento, Universidade Federal do Paraná no ano de 2007 (ALENCASTRO, 2007).

${ }^{2}$ Recorre-se à definição de ethos cultural, fundamentada em Bourdieu: é um sistema de valores implícitos e interiorizados, que definem as atitudes face ao capital cultural, ou seja, uma rede de significados e práticas profundamente conectados ao fazer e no como fazer as coisas do mundo (BOURDIEU, 1998).

${ }^{3}$ Ulrich Beck (1992), em seu livro Risk Society, towards a new modernity (Sociedade de Risco, em direção a uma nova modernidade), apresenta uma nova perspectiva para a compreensão da dimensão mais profunda de acidentes e de seus danos e impactos para a vida. Para Beck, a produção social da riqueza é sempre acompanhada por uma produção social de risco. O processo de industrialização é indissociável do processo de produção de riscos, dado que uma das principais consequências do desenvolvimento científico industrial é a exposição da humanidade a riscos e inúmeras modalidades de contaminação, nunca observadas anteriormente, constituindose, portanto, em ameaças para os habitantes e para o meio ambiente. O problema é ainda maior porque os riscos gerados hoje não se limitam à população atual, uma vez que as gerações futuras também serão afetadas de forma até mais grave.
} 
remotos e cumulativos da intervenção negativa sobre a natureza, passam a exigir uma nova reflexão no campo da ética; uma ética que evite, mediante contenções voluntárias, que o poder tecnológico conduza os homens a um desastre. Para ele, pela primeira vez na história, as ações humanas parecem irreversíveis: Prometeu ${ }^{4}$ está liberto e o mal-estar cresce ao redor da Terra.

O centro nevrálgico da formulação de Jonas é sempre a possibilidade de que não seja mais possível reverter esse quadro. No Princípio Responsabilidade, propôs um sistema ético que pudesse superar o do relativismo predominante na sociedade atual, marcada pela conquista de um inusitado poder: o da tecnologia moderna. Jonas considerou que a humanidade, de posse de um poder até então inexistente, necessitaria de uma ética que norteasse seus atos, não somente no plano individual, mas, sobretudo, no âmbito coletivo e político, pois são ações que produzem efeitos e possuem abrangência espaço-temporal de tal ordem que, em épocas anteriores, não poderiam ter sido cogitados devido à inexistência, ainda, de tais condições.

São as consequências do poder tecnológico que motivaram Hans Jonas a rever, de forma radical, o conceito de responsabilidade ética, pois a sociedade não tinha se deparado com problemas de tal magnitude. Hans Jonas coloca a responsabilidade no centro da ética, circunscrevendo-a no horizonte espaço-temporal proporcional aos efeitos das ações tecnológicas. Por conseguinte, uma nova teoria sobre a responsabilidade caracteriza-se como eixo principal de toda sua obra.

A seguir, serão apresentados os aspectos gerais da teoria ética desenvolvida por Hans Jonas: as bases filosóficas em que se apoia para estabelecer o cuidado para com a natureza e as gerações futuras, os problemas éticos trazidos pelas novas tecnologias, a inadequação das éticas tradicionais e seus dois grandes princípios orientadores, a "heurística do medo" e o "novo imperativo ético".

\section{Uma metafísica da natureza}

A proposta de Jonas não trata da transformação do homem pela transformação das relações sociais, mas sim, da preservação da essência humana diante dos percalços desmedidos do seu próprio poder.

Ao abordar a questão da essência humana, Hans Jonas incorre invariavelmente numa metafísica. Tradicionalmente a metafísica é a parte mais central da filosofia, a "filosofia primeira", na medida em que se ocupa dos princípios e das causas primeiras. Ao considerá-la como uma reflexão definitiva sobre o significado das coisas e dos entes, na qual o pensador metafísico procura algo basilar, firme, permanente, a partir do qual interpreta a dinâmica das coisas e dos homens, e que este elemento basilar chama-se substância, fundamento ou essência ou modelo de interpretação do mundo, fica fácil perceber que toda a argumentação de Hans Jonas sustenta-se na metafísica, a única instância a partir da qual é permitido "que se pergunte por quê, afinal, homens devem estar no mundo" (2006, p. 22).

É a metafísica que possibilita os questionamentos sobre o sentido da existência humana e da vida, seus valores e princípios. E é por meio dela que Jonas justifica que é melhor uma vida equilibrada do que o reino da destruição, da barbárie, do relativismo e do niilismo. O valor da vida é para Jonas uma categoria ontológica, um princípio fundamental e orientador, capaz de construir o próprio sentido da existência humana.

Contrapondo-se à predominância de uma tendência dominante no pensamento filosófico contemporâneo, que sugere que toda ética deve estar embasada no sujeito autônomo, responsável e determinador de suas próprias leis, sem recorrências à autoridade ou justificativas exteriores, Jonas propõe, para que não se incorra em subjetivismos e relativismos, que a ética deva estar fundada em uma doutrina do Ser - uma ontologia 5 .

\footnotetext{
${ }^{4}$ Prometeu - personagem da mitologia grega que, tendo roubado o fogo dos deuses para entregá-lo aos homens, foi acorrentado, como castigo, no monte Cáucaso, no meio de uma colina, e uma águia de longas asas enviada por Zeus comia-lhe o fígado imortal. Ao cabo do dia, chegava a negra noite por Prometeu ansiada, e seu figado tornava a crescer. Diz-se, em geral, das pretensões humanas que, de alguma forma, buscam superar os limites da condição humana e igualar-se aos deuses, e, também, das tentativas do homem de superar a si mesmo, por meio da ciência e da técnica para dominar a natureza (JAPIASSÚ; MARCONDES, 1991, p. 203).

${ }^{5}$ Ligado ao pensamento metafísico, a ontologia é o estudo do "ser enquanto ser"; o ser é considerado independentemente de suas determinações particulares e da sua inteligibilidade própria. A ontologia, como teoria do ser, é uma ciência que aborda o ente (ser) em geral, e não sobre este ou aquele ente em particular, designado por um nome especial ou por certas propriedades particulares (ABBAGNANO, 1998, p. 660-666).
} 
A presença dos homens - no futuro - deve ser preservada, o que obriga as gerações presentes - as únicas que podem ameaçá-la - que se tornem responsáveis por ela. Só assim a ideia de homem (um construto ontológico) pode ser garantida.

O porquê da existência humana e, particularmente, das gerações futuras, é a questão central a ser resolvida: trata-se da tarefa de se assegurar a presença do homem na Terra. Jonas, dessa forma, aborda o papel da ética de modo radical, pois a alternativa moral que se propõe discutir é a tensão entre o ser e o não-ser, existência ou não-existência.

O âmago do problema da concepção científica e da especialização tecnológica, para Jonas, que neste aspecto se aproxima de seu mestre Heidegger, é o esquecimento do Ser e o distanciamento das coisas em sua raiz original - da essência, pois o que predomina é aproximação, objetiva e contínua, da utilidade imediata das coisas. Em outras palavras, "a ameaça que pesa sobre o homem não vem, em primeiro lugar, das máquinas e equipamentos técnicos, cuja ação pode ser eventualmente mortífera. A ameaça, propriamente dita, já atingiu a essência do homem" (HEIDEGGER, 2002, p.30-31).

Os efeitos da tecnologia sobre a existência humana, sobretudo sobre a essência do homem e da própria vida, levaram Jonas a abrigar os fundamentos de sua ética em uma instância ontológica. Dessa forma, só a metafísica permite a Hans Jonas fazer as perguntas: "vale a pena existir?" (2006, p.22) e "por que afinal os homens devem estar no mundo?” (2006, p.101). Assim, ele retoma uma questão já proposta por Leibniz ${ }^{6}$ - "por que existe algo e não o nada?" (JONAS, 2006, p.100), ao que responde [em consonância com Leibniz]: "porque algo deve existir, de preferência ao nada, seja qual for a causa que o tenha feito existir" (JONAS, 2006, p.102). A conclusão é que, obrigatoriamente, o Ser vale mais que o não-Ser, e há uma predominância absoluta da existência em relação ao nada. "A existência de um mundo é sempre melhor do que a existência de nenhum" (JONAS, 2006, p.45). A conclusão é que deve preservar-se o mundo físico (morada do homem) para que as potenciais condições de existência permaneçam intactas.

Jonas também recorre à biologia como apoio à sua metafísica. Para ele, com o surgimento da vida, a distinção existencial entre existir e não existir começa a ter significado: a vida tende tenazmente a manter-se no plano da existência, e isso se dá mediante a elaboração de habilidosos atos de autopreservação, cuja única finalidade é evitar seu oposto, ou seja, a morte.

A preservação da vida não é reservada apenas aos humanos, mas é um imperativo que recai sobre os humanos exatamente pelo fato de que são os seres mais desenvolvidos da natureza, o que lhes confere especial responsabilidade. A obrigação dessa responsabilidade recai sobre o homem, pois, "dentro do mundo conhecido, a capacidade para esta, como para qualquer outra idéia, se manifesta unicamente no humano" (JONAS, 2004, p. 271).

Para Jonas, o homem precisa reconhecer esse chamado da natureza para ser seu guardião; além do mais, o presente é governado por um imperativo de que se preserve a essência humana para sempre, e isso porque ela é proveniente de um processo natural, que é bom. Por conta disso, a responsabilidade humana existe para aquilo que a permitiu vir à existência, ou seja, para com a natureza em si, e, primeiramente, com os outros seres humanos. Ao tentar justificar a responsabilidade para com as futuras gerações, uma responsabilidade não-recíproca, Jonas (2006, p.90) o faz utilizando uma comparação com o dever que os pais têm para com os filhos, o que para ele seria o arquétipo de toda a ação responsável, e que se encontraria poderosamente implantado pela natureza nos seres humanos.

O grande problema que se instaura nessa perspectiva é extrapolar o altruísmo existente nas relações entre pais e filhos para o conjunto da sociedade e - mais difícil ainda - para a humanidade futura. Para isso, se apoia na metafísica, ou seja, o imperativo da obrigação de ser e de continuar sendo (no futuro) não deriva de uma doutrina do agir, mas "da metafísica como doutrina do Ser, da qual a idéia do homem faz parte" (JONAS, 2006, p. 95).

$\mathrm{O}$ fundamento da responsabilidade que se tem para com filhos não é um relacionamento ôntico para com eles

\footnotetext{
${ }^{6}$ Representando a corrente do "otimismo filosófico", Leibniz defendeu a ideia de que "todo possível existe se um mais perfeito não impede a sua existência". Em outras palavras, se existe alguma coisa ao invés do nada é porque: (1) há possíveis; (2) esses possíveis têm alguma inclinação para existir; (3) essa inclinação é igual a sua perfeição. Conclui-se que o mundo foi criado porque era melhor que alguma coisa e porque era o melhor de todos, ou seja, "entre uma infinidade de mundos possíveis, há o melhor de todos [o nosso], caso contrário Deus não teria chegado a criá-lo” (JAPIASSU; MARCONDES, 1991, p. 187).
} 
em particular, mas um dever para com toda a humanidade: a ideia de humanidade é parte de uma ideia contida nos propósitos da natureza. O bem em si é a natureza vivente, incluindo a humanidade como sendo a mais alta expressão dos propósitos da natureza.

Por que cuidar de uma humanidade futura e do planeta? Hans Jonas (2006, p. 232-233) responde categoricamente: pelo dever de se "manter aberto o horizonte da possibilidade, que no nosso caso, foi dado junto com a existência da espécie". Para tanto, é necessário que se garanta a "existência da humanidade em um ambiente satisfatório", ou seja, o "futuro da humanidade inclui, obviamente, o futuro da natureza como sua condição sine qua non" (2004, p.229).

Os homens não são aliens acoplados a uma máquina sem vida, mas cidadãos de uma comunidade biótica abundante de vida. A existência humana está, portanto, intrinsecamente ligada à sobrevivência da natureza.

\section{A tecnologia como um problema ético}

O Princípio Responsabilidade, concebido como um Tractatus tecnológico-ethicus, tem como objetivo fundamentar filosófico-metafisicamente uma ética para as gerações futuras, na tentativa de salvaguardá-las da hybris ${ }^{7}$ da intervenção e da manipulação tecnológica que se préanuncia na atualidade.

Com as modernas tecnologias, poder-se-ia dizer que a humanidade teria atingido o ideal baconiano - da dominação da natureza pela técnica científica. Atribui-se a Francis Bacon a concepção do lema "saber é poder", que revela sua firme disposição de ânimo em fazer dos conhecimentos científicos um instrumento prático de controle da realidade (REALE; ANTISERI, 1991, p.329). Mais tarde, seguindo uma orientação semelhante, René Descartes, na sexta parte do seu Discurso do Método, afirmou que era possível ao homem chegar a conhecimentos que fossem úteis à vida e que a aplicação desses conhecimentos transformaria os homens em "senhores e possuidores da natureza" (1996, p. 69). Tanto para Bacon como para Descartes, a atuação da ciência, que ainda estava em fase inicial, visava ao bem-estar da humanidade e à produção de descobertas que facilitassem a vida humana na Terra, e anunciava a promessa de vida melhor.

Sabe-se que o desenvolvimento científico e tecnológico da segunda metade do século XX contribuiu para criar o mito da autonomia da ciência, elevando, em muito, seu status em face das outras formas de conhecimento, incorporando inclusive uma espécie de caráter ideológico, que, para Marcuse, assumiria "em si todas as esferas da cultura" (apud HABERMAs, 1993, p.49).

Sobre essa questão, Heidegger (1997) ensinava que o mundo humano tinha se transformado em um universo técnico, no qual todos estão presos. Trata-se, assim, de uma civilização que se consuma e se consome em nível exclusivo do fazer e na qual o compreender torna-se obsoleto e sem sentido.

Se, antes da revolução industrial, a técnica era um tributo prestado à necessidade, agora é a mais significativa tarefa humana. O homo faber adquiriu o primado sobre o homo sapiens. Nada é mais ameaçador do que este sucesso da tecnologia. O domínio da natureza pelas ciências e pelas tecnologias se transforma no projeto central das sociedades modernas. A técnica, antes um simples meio, passa a ser, como moderna tecnologia, a própria finalidade.

Hoje é quase impossível agir independentemente da tecnologia - o que implicaria a idéia de prioridade das intenções [fins à procura de meios adequados]; o que acontece é que a escolha dos fins é grandemente determinada pelas tecnologias disponíveis. Ou seja, "a técnica moderna propõe ela própria finalidades inéditas, que não seria possível imaginar antes do seu aparecimento". Em muitas situações, "a técnica impõe à ação finalidades inéditas” (LADRIÈRE, s.d., p. 12).

Para Heidegger (2006, p. 46-47), a técnica e seu modus vivendi (cálculo, planejamento etc.), não seria mais um meio, um instrumento do qual o homem moderno se serviria para seus objetivos. Ela já teria transformado internamente o ser humano.

O domínio da técnica sobre a natureza, porém, veio acompanhado de inúmeros resultados inesperados. A incrível extensão do poder alcançado pelo progresso técnicocientífico, e da necessidade imperativa do seu emprego,

\footnotetext{
${ }^{7} \mathrm{O}$ termo hybris, intraduzível em línguas modernas, para os gregos significava qualquer violação da norma da medida, ou seja, dos limites que o homem deve encontrar em suas relações com os outros homens, com a divindade e com a ordem das coisas (ABBAGNANO, 1998, p. 520).
} 
conduziu a humanidade a uma espécie de impotência em administrar as consequências imprevisíveis $\mathrm{e}$ - muitas vezes - destrutivas deste mesmo progresso. Hans Jonas chama a atenção para este complicado paradoxo. Para ele,

[...] Bacon não poderia imaginar um paradoxo desse tipo: o poder engendrado pelo saber conduziria efetivamente a algo como um "domínio" sobre a natureza (ou seja, à sua superutilização), mas ao mesmo tempo a uma completa subjugação a ele mesmo. O poder tornou-se autônomo, enquanto sua promessa transformou-se em ameaça, e sua perspectiva de salvação em apocalipse (2006, p. 236-237).

Um outro aspecto dos riscos das modernas tecnologias, apontado por Hans Jonas, é o fato de que, durante muito tempo, a entidade 'homem' apareceu como constante e situada fora do campo da techné transformadora; contudo, hoje as modernas tecnologias, particularmente as biotecnologias, são capazes de introduzir elementos completamente novos e fazer, do homem, o objeto do seu agir. "O próprio homem passou a figurar entre os objetos da técnica. O homo faber aplica sua arte sobre si mesmo e se habilita a refabricar inventivamente o inventor e o confeccionador de todo o resto" (2006, p. 57). O prolongamento da vida, o controle do comportamento humano e a manipulação genética testemunham de forma contundente esse salto qualitativo no agir humano.

Sendo assim, nem a natureza nem a natureza humana podem ser tomadas como dados últimos e imutáveis para, com base neles, erguer-se uma avaliação ética dos efeitos da ação tecnológica. A tendência utópica e o poder da tecnologia exigem escolhas no que antes eram especulações. A grandeza do poder tecnológico modificou totalmente a distância entre questões próximas e remotas, entre as esferas da prudência e da sabedoria. Exige-se, dessa forma, uma nova responsabilidade, coextensiva à escala da excessiva grandeza do poder humano, na qual, cada escolha imediata exija o conhecimento das suas consequências remotas.

O progresso tecnológico dotou o homem de poder de ação que ultrapassa, em muito, tudo o que poderia ter sido suposto anteriormente. $\mathrm{O}$ aparecimento das novas tecnologias, propiciadoras de um crescimento brutal dos poderes humanos (de um homem que é ao mesmo tempo sujeito e objeto de suas próprias técnicas), fez surgir o receio das nefastas consequências dos grandes poderes tecnológicos em ação. Por essa razão, não há mais espaço para argumentações em torno da neutralidade da ciência e da técnica.

Se a "ética tem a ver com o agir, a conseqüência lógica disso é que a natureza modificada do agir humano [pela ciência e tecnologia] também impõe uma modificação na ética" (JONAS, 2006, p.29). Há, portanto, a necessidade da regulamentação, por meio de normas, do emprego de todo esse poder técnico-científico. Mas que orientação ética seria capaz de fazê-lo?

\section{Um novo papel para a ética}

Para Hans Jonas, as premissas éticas conhecidas já não são válidas e cabe ao homem refletir sobre sua condição moral diante da mudança da natureza da ação humana, tecnologicamente potencializada, em outras palavras: "a natureza qualitativamente nova de muitas das nossas ações descortinou uma dimensão inteiramente nova de significado ético, não prevista nas perspectivas e nos cânones da ética tradicional" (2006, p.29).

Ele chama a atenção para o fato de que, nas éticas tradicionais, os efeitos positivos e negativos resultantes do agir humano só eram considerados num limite espaçotemporal próximo ao agir. $\mathrm{O}$ bom e o mau geralmente se referiam aos bens próximos. Em uma perspectiva de longo prazo, tudo era considerado destino ou providência. As máximas tradicionais dos filósofos e cientistas referiam-se ao imediato, em que todos partilhavam um tempo presente comum.

[...] O alcance efetivo da ação era pequeno, o intervalo de tempo para previsão, definição de objetivo e imputabilidade era curto, e limitado o controle sobre as circunstâncias. O comportamento correto possuía seus critérios imediatos e sua consecução quase imediata. $\mathrm{O}$ longo trajeto das conseqüências ficava ao critério do acaso, do destino ou da providência. Por conseguinte, a ética tinha a ver com o aqui e agora, como as ocasiões se apresentavam aos homens, com as situações recorrentes e típicas da vida privada e pública. $\mathrm{O}$ homem bom era o que se defrontava virtuosa e sabiamente com essas ocasiões, que cultivava em si a capacidade para tal, e que no mais conformava-se com o desconhecido (JONAS, 1994, p. 36-37). 
E também, "nenhuma ética anterior tinha de levar em consideração a condição global da vida humana, o futuro distante e até mesmo a existência da espécie" (JONAS, 1994, p. 40). Os efeitos remotos eram relegados ao acaso. É neste tocante que reside toda a diferença, pois que, para Jonas, a ação humana, tecnologicamente potencializada, pode danificar irreversivelmente a natureza e o próprio homem. Tem-se, dessa forma, uma nova dimensão para a responsabilidade - não prevista pelas éticas tradicionais - que seja capaz de interagir com novas ordens de grandeza em termos de consequências futuras para a ação humana.

Jonas alerta para o fato de que,

[...] Nenhuma ética tradicional nos instrui, portanto, sobre as normas do "bem" e do "mal" às quais se devem submeter as modalidades inteiramente novas do poder e de suas criações possíveis. O novo continente da práxis coletiva que adentramos com a alta tecnologia ainda constitui, para a teoria ética, uma terra de ninguém (2006, p.21).

Destarte, as concepções clássicas de ética não propiciam bases ao homem hodierno para lidar com as novas possibilidades de sua intervenção, como, por exemplo, as difíceis questões trazidas pelo poder de destruição das armas nucleares e pelos experimentos ligados às mais diversas formas de manipulação genética, visto que não eram tangíveis em épocas anteriores. A ética deve, portanto, ser renovada e ampliada em larga medida. Os antigos preceitos, tais como o amor ao próximo, podem (e devem) permanecer, mas o escopo da ética deve abarcar, na atual conjuntura, outros horizontes.

A capacidade de intervenção humana sobre a natureza atribui ao homem um poder imenso, e Jonas questiona "se estamos qualificados para esse papel demiúrgico", ou seja, "a questão mais grave que se pode colocar para o homem, que se descobre subitamente de posse de tal poder sobre o destino" (2006, p.42).

Situações sem precedentes, relacionadas à crise ambiental e ao risco tecnológico estão provocando mutações no que concerne ao agir humano. Situações que até então estavam em esfera exterior à vontade, tidas como produtos do acaso, catástrofes naturais, por exemplo, hoje podem ser reportadas, em certo ângulo, às consequências das ações humanas. Isso se deve, em especial, ao grande avanço tecnológico conquistado pela civilização atual.
A crise ambiental contemporânea colocou em xeque teorias clássicas, pois são teoricamente insuficientes para resolver os dilemas que ora são colocados em discussão. As questões concernentes à sobrevivência do planeta exigem reformulações. Evidencia-se, cada vez mais, que as doutrinas éticas e políticas tradicionais carecem de séria atualização, pois têm como base premissas sobre a condição humana que a atualidade tecnológica alterou profundamente.

$\mathrm{O}$ alcance do agir humano foi modificado pelo desenvolvimento e está relacionado ao potencial tecnológico moderno e às deformações ideológicas introduzidas na modernidade.

As teorias éticas tradicionais desenvolveram-se em uma época em que a atmosfera e os oceanos pareciam recursos ilimitados, e as responsabilidades e os danos eram, de modo geral, claros e bem definidos. Se um homem agredisse outro, era bem claro e definido quem agredia e quem era agredido. Atualmente, os problemas na camada de ozônio e das mudanças climáticas, por exemplo, trouxeram à tona uma nova e inusitada espécie de dano moral. Ações atuais corriqueiras, como um novaiorquino que, ao usar desodorante aerossol (que contém CFC - clorofluorcarboneto - um composto de gás nocivo), pode estar provocando a morte, por câncer de pele, muitos anos mais tarde, de pessoas que vivem em Punta Arenas, no Chile; quando qualquer indivíduo dirige um carro, o motor do automóvel libera dióxido de carbono, que aumenta o efeito estufa e, em longo prazo, provoca, de certa maneira, inundações em Bangladesh. Como mudar a ética para que possa nortear essa nova situação? (SINGER, 2004, p. 26).

Dos grandes empreendimentos tecnológicos, tais como usinas nucleares, às mais modestas ações cotidianas, como dirigir um carro ou usar aerossol, tudo parece contribuir para algum tipo de impacto ambiental, muitos deles, tomados nas devidas proporções, virtualmente catastróficos.

Outro ponto interessante trazido à baila por Jonas diz respeito ao fato de que a cultura ocidental sempre comportou uma ética antropocêntrica e simétrica, que abarca apenas as relações entre as pessoas. A ética até então "dizia respeito ao relacionamento direto de homem com homem, inclusive o de cada homem consigo mesmo; toda ética tradicional é antropocêntrica" (2006, p. 35).

Porém, os novos fatos apontam para a necessidade de extensão e expansão da ética. Da mesma forma que, nos 
últimos séculos, as diferentes teorias éticas assumiram um caráter de inclusão mais universal, procurando contemplar todas as pessoas (embora escravos e mulheres não fizessem parte das preocupações éticas de algumas teorias clássicas), hoje em dia as formulações éticas tendem a incorporar não somente os seres humanos, mas também a natureza e as gerações futuras.

Jonas sugere que o escopo da ética deve se alargar e incluir em suas preocupações as relações entre os seres humanos e o mundo não humano, envolvendo os animais, a natureza e, até mesmo - aqui talvez uma nova instância -, os artefatos tecnológicos. Cabe então

[...] repensar os princípios básicos da ética. Procurar não só o bem humano, mas também o bem de coisas extra-humanas, ou seja, alargar o conhecimento dos "fins em si mesmos" para além da esfera do homem e fazer com que o bem humano incluísse o cuidado delas (2006, p. 23).

O cuidado para com as coisas extra-humanas inclui a natureza, que deve ter uma significação ética própria, autônoma e independente da condição de simples meio para a satisfação das necessidades humanas. Rompe-se, assim, com a milenar tradição que colocou o homem na condição de ápice da criação, imagem e semelhança de Deus, e com pleno domínio sobre a natureza.

Nessa nova ética concebida por Jonas, a responsabilidade assume condição fundamental: "a natureza como uma responsabilidade humana é seguramente o novum sobre o qual uma nova teoria ética deve ser pensada" (2006, p.39).

Jonas não deprecia as tradicionais prescrições de caridade, honestidade, virtude e justiça, pois todas mantêm seu valor no dia a dia e nas relações pessoais. Mas o predomínio crescente da ação coletiva, ou da soma das ações dos indivíduos, teve a sua natureza modificada, e todos os atos e feitos são, agora, passíveis de serem potencializados pelo imenso poderio tecnológico disponível. Há, portanto, a exigência de uma nova e radical responsabilidade. Para ele,

[...] as antigas prescrições da ética "do próximo" - as prescrições da justiça, da misericórdia, da honradez, etc. - ainda são válidas, em sua imediaticidade íntima, para a esfera mais próxima, quotidiana, da interação humana. Mas essa esfera torna-se ensombrecida pelo crescente domínio do fazer coletivo, no qual ator, ação e efeito não são mais os mesmos da esfera próxima. Isso impõe à ética, pela enormidade de suas forças, uma nova dimensão, nunca antes sonhada, de responsabilidade (2006, p. 39).

Nesse ponto ele está muito próximo de Paul Ricoeur (2000, p.15-22), para quem a idéia de responsabilidade vigente atualmente aproxima-se muito mais de uma limitada noção jurídica que de um conceito moral abrangente. Ou seja, a única preocupação recai sobre qual é a responsabilidade da ação de alguém, quando essa ação causa algum tipo de dano. Nesse contexto, quem causa dano deverá responder por ele, reparando-o. Ricoeur chama a atenção para as limitações dessa visão de responsabilidade e sugere uma espécie de "responsabilidade social e coletiva", na qual o sentido tradicional (imputação) deveria ser transposto para um outro, que tenha nos conceitos de cuidado e prudência (previsão e avaliação das implicações da ação) sua tônica principal. Isso se deve à expansão dos riscos - muitos, incalculáveis - provenientes do imenso potencial tecnológico que se tem em mãos, hoje em dia.

Jonas também retorna ao conceito de prudência. A prudência considera a existência do acaso, da incerteza, do risco, do desconhecido, componentes da realidade científica em que a modernidade está imersa. É ela - a prudência - que possibilita certa previsibilidade para com o futuro, tão necessária na discussão dos resultados da ciência e da tecnologia. A prudência, também, determina o que é necessário escolher e o que é necessário evitar. $\mathrm{O}$ grave e nocivo equívoco está, na maioria das situações, na não observância dessa última categoria - o evitar. Decorre, pois, que adotar a prudência no sentido moderno do termo, deve ser no sentido de precaução. A prudência está ligada à sabedoria, à capacidade de se determinar o que é bom e mau para o ser humano, e deve-se, então, adotá-la regida pela conduta racional das atividades humanas, e da melhor maneira de ser conduzida ${ }^{8}$.

Para Jonas, no entanto, e isso o diferencia de todos os outros, a responsabilidade é ontológica e refere-se ao futuro longínquo da humanidade, estendendo-se aos descendentes, ou seja, abarca um futuro ilimitado. Deve-se ter responsabilidade para com uma humanidade que ainda

\footnotetext{
${ }^{8}$ Sobre o conceito de Prudência, ver ABBAGNANO (1998, p. 863-864).
} 
não existe; ser responsável por outras pessoas que ainda estão por nascer e que, por conta disso, não podem, ainda, reivindicar para si um ambiente saudável para viver. Não é uma relação de reciprocidade, tal como prescrito nas éticas tradicionais. O dever para com os descendentes é muito profundo e só pode ser entendido quando se compara com o que as éticas tradicionais sugerem, no caso dos deveres dos pais para com os filhos, um dever de total entrega e não reciprocidade para com o outro. Como já comentado anteriormente, esse tipo de responsabilidade é "o arquétipo de toda a ação responsável, arquétipo que, felizmente, não precisa de nenhuma dedução a partir de um princípio, senão que se encontra poderosamente implantado pela natureza em nós" (2006, p. 90).

A responsabilidade para com as gerações vindouras é contínua e refere-se ao futuro. A responsabilidade parental concerne à criança, encarada como um ser total, e não somente por suas necessidades imediatas. Ela não admite pausas, é contínua, porque é a vida do objeto que prossegue sem interrupção, e se refere sempre ao futuro da existência da criança.

\section{A heurística do temor e um novo imperativo ético}

Diante da incerteza e do risco tecnológico, a resposta que Jonas oferece é sempre precaução e cautela, pois, para ele, a ação deve ser sempre avaliada em função dos seus piores prognósticos. Considerando as possibilidades de riscos e danos insanáveis, inclusive para as gerações futuras, a proposta que nos oferece é uma abordagem extremamente cuidadosa das situações a serem avaliadas. Escolhe-se, de forma conservadora, a possibilidade da ocorrência das piores situações.

As possibilidades e a previsão que o saber teórico tem à disposição não são mais suficientes para acompanhar o saber tecnológico e seu poder de atuação. Há, portanto, um descompasso entre a previsibilidade e o poder efetivo da ação. A cautela é necessária, e Jonas propõe uma "heurística do temor", na qual, deve-se conceder, em situações de incerteza, precedência ao pior prognóstico no que diz respeito às conseqüências da ação. Se anteriormente "o braço curto do poder humano não exigia um longo braço de conhecimento preditivo" (1994, p. 37), agora, a consciência no agir, em todas as suas etapas e desdobramentos futuros, passa a se opor às posturas imediatistas e fragmentadas. Em outras palavras,

[...] A complexidade das relações causais na ordem social e na biosfera, que desafia qualquer cálculo (inclusive o eletrônico); o caráter essencialmente insondável do homem, que sempre nos reserva surpresas; e a imprevisibilidade, ou seja, a incapacidade de prever as futuras invenções. [...]. Em todo caso, a extrapolação requerida exige um grau de ciência maior do que o que já existe no extrapolandum tecnológico (JONAS, 2006, p.73).

O exemplo do DDT (Dicloro-Difenil-Tricloroetano), pesticida desenvolvido durante a Segunda Guerra para o combate aos mosquitos causadores da malária, é emblemático por representar a incapacidade que a ciência muitas vezes tem para identificar as consequências futuras de seus inventos. Esse inseticida, cujo inventor recebeu o Prêmio Nobel, ao ser introduzido para uso no combate a pragas, terminou por mostrar que a natureza é vulnerável à intervenção humana. A maior parte dos pesticidas até então conhecidos era efetiva contra um ou outro tipo de insetos, mas o DDT era capaz de destruir, de imediato, centenas de espécies diferentes. Na Europa, por exemplo, começou a ser usado sob a forma de pó, eficiente contra pulgas e outros pequenos insetos.

Contrariando o sucesso deste inseticida, Rachel Carson, no livro Silent Spring (A Primavera Silenciosa), lançado em 1962, mostrou como o DDT penetrava na cadeia alimentar e acumulava-se nos tecidos gordurosos dos animais, inclusive do homem (chegou a ser detectada a presença de DDT até no leite humano), com o risco de causar câncer e dano genético.

A grande polêmica movida pelo instigante e provocativo livro é que não só expunha os perigos do DDT, como também questionava de forma eloquente a confiança cega da humanidade no progresso tecnológico. Dessa forma, o livro possibilitou abrir espaço para o movimento ambientalista que se seguiu.

Esse tipo de constatação motivou Hans Jonas a consolidar a nova relação de responsabilidade com a natureza, que agora se encontra em poder do ser humano,

[...] uma nova espécie de humildade - uma humildade não como a do passado, em decorrência da pequenez, 
mas em decorrência da excessiva grandeza do nosso poder, pois há um excesso do nosso poder de prever e sobre o nosso poder de conceder valor e julgar (2006, p. 63).

Ao ser humano cabe a escolha entre extremos e suas consequências, e nenhum saber prévio pode fornecer apoio seguro para as possibilidades e capacidades de valorar, agir, julgar e escolher. Jonas (2006, p. 76-77) afirma que a "impotência de nosso saber com respeito a prognóstico de longo prazo" faz com que, "nos assuntos dessas eventualidades capitais se dê mais peso à ameaça do que à promessa". Torna-se, portanto, "necessário dar mais ouvidos à profecia da desgraça do que à profecia da salvação".

O Princípio da Precaução, ao preconizar que "dada a ausência de certezas, levando-se em conta os conhecimentos científicos e técnicos do momento, não se deve retardar a adoção de medidas efetivas e em exata proporção que visem prevenir um risco de prejuízos graves e irreversíveis ao meio ambiente, a um custo economicamente aceitável" (MOndello, 1998) é, obviamente, influenciado pela heurística do temor, de Jonas.

Como consequência, Jonas estabelece seu imperativo ético geral. A expressão 'imperativo ético' remete a Kant e ao preceito por ele concebido de se agir segundo uma regra que se transforme em uma lei geral (universal) ${ }^{9}$. A ética kantiana busca, na razão, formas de procedimentos morais práticos que possam ser universalizáveis, sendo que um ato moral, para Kant, deve conter os princípios que um indivíduo segue, e que são, necessariamente, bons. É uma ética formal porque se propõe a postular um dever para todos os homens, independentemente de sua situação social, seja qual for o seu conteúdo concreto, e é autônoma, pois garante a autonomia da ação individual, mas requer o compromisso e, por ser concebida como universal, todos devem seguir.

Em face das novas dimensões espaço-temporais do agir humano, partindo da constatação de que não é possível adaptar o imperativo kantiano à atual civilização tecnológica, Jonas propõe um novo imperativo ético, que é "aja de modo a que os efeitos da tua ação sejam compatíveis com a permanência de uma autêntica vida humana sobre a Terra" ou, expresso negativamente, "aja de modo a que os efeitos da tua ação não sejam destrutivos para a possibilidade futura de uma tal vida" ou, simplesmente, "não ponha em perigo as condições necessárias para a conservação indefinida da humanidade sobre a Terra" (2006, p. 47-48).

Para ele, o imperativo não é mais uma questão de uma máxima subjetiva a ser aplicada a uma comunidade de seres racionais, como queria Kant, mas uma máxima que parte da objetividade dos efeitos do agir coletivo, cuja realidade afeta a humanidade.

Jonas (1998, p. 69-70) aponta para a importância das consequências de longo prazo das ações humanas. Antes de agir é preciso avaliar a ação segundo o imperativo da vida humana. Já não mais se justifica a ação desprovida de responsabilidade. Uma 'ética para o futuro', que começa hoje, deve ter em vista as gerações futuras, enxergue o amanhã e se proponha a proteger os futuros descendentes da humanidade das conseqüências das ações presentes, executadas sob o signo da globalização da tecnologia, cujo potencial e consequências são imprevisíveis e potencialmente perigosas.

$\mathrm{O}$ futuro da humanidade tem de ser incluído nas escolhas presentes. Não se tem o direito de escolher ou de arriscar a não-existência de gerações futuras por causa da atual. Há agora, também, um dever para com o que ainda não existe.

Esse novo imperativo dirige-se à dimensão pública e não à ação privada (como no imperativo kantiano). A sua destinação não é a esfera das relações singulares, mas situase no domínio da ação política pública. A universalização se dá a partir da objetividade dos efeitos do agir coletivo, que afeta a humanidade como um todo (GIACÓIA, 2000, p. 193-206).

Num período da história em que a humanidade vive sob a sombra do niilismo, sem normas objetivas, a universalidade deve ser capaz de lidar com a multiplicidade de valores que emergem a cada dia; o "princípio responsabilidade" se configura em uma confissão de uma nova e paradoxal humildade, a de que o poder humano é infinito e ao mesmo tempo insignificante diante dos próprios desdobramentos e consequências de sua aplicação.

\footnotetext{
${ }^{9} \mathrm{~A}$ ética kantiana busca formas de procedimentos práticos que possam ser válidos universalmente, uma vez que concebe como sendo um ato moralmente bom aquele que é praticado por todos, indistintamente. "Age apenas segundo uma máxima tal que possas ao mesmo tempo querer que ela se torne lei universal" (KANT, 1984, p. 129).
} 


\section{Restrições às teorias de Hans Jonas}

Jonas (2006, p. 92) reconhece que seu trabalho possibilita uma série de objeções, principalmente porque "contraria os dogmas mais sólidos no nosso tempo: primeiro que não existem verdades metafísicas [o problema da fundamentação última da ética] e, segundo, que não se deixa deduzir do Ser um dever [falácia naturalista]".

Críticas não faltaram ao seu trabalho. Seu grande amigo e interlocutor, o filósofo Günther Anders, por exemplo, era um dos que afirmava que as fundamentações éticas, religiosas e filosóficas, propostas no decorrer da história, apresentam-se hoje como obsoletas. Para ele, o empreendimento de Jonas, em fundar uma nova ética, era absolutamente utópico e que buscar recursos em uma metafísica era - a partir de gesto clássico - recuar no tempo (RÖPCKE; DAVID, 2004, p. 195-203).

De fato, ao procurar fundar a ética na vida - atribuindo a ela um valor inerente e afirmando que há a obrigação de se garantir sua viabilidade futura -, Jonas recai, implicitamente, em uma metafísica da vida, sendo que é uma tentativa de colocar a ética em base objetiva, contrastando com o subjetivismo que tem caracterizado a maioria dos sistemas éticos atuais (HABERMAS, 2004, p. 23-26).

Outro recurso muito utilizado para se fundamentar a ética é a crença de que a natureza deve servir de guia para o agir moral, devendo o homem interpretá-la para dali extrair premissas factuais para delas derivar a normatividade. Hans Jonas, sem dúvida, usa esse recurso, o que pode colocar sua teoria ética em uma situação delicada e sujeita às críticas da falácia naturalista ${ }^{10}$.

Interessante notar que, na sociedade atual, o altruísmo, concebido como um princípio permanente da vida, como quis Hans Jonas, é um valor depreciado, equiparando-se a uma vã mutilação da própria pessoa (LIPOVESTKY, 2005, p. 107).

Não há nenhum imperativo que obrigue, por exemplo, um canadense a restringir-se do uso de calefação, no inverno, em prol das gerações futuras. A alegação seria de que sem calefação não seria possível viver em muitas partes daquele país. O consumo de energia é intenso e, ao mesmo tempo, vital, mas o interesse em poupá-lo para as gerações futuras passa, imediatamente, para o segundo plano.

Por que as gerações presentes devem agir de maneira altruísta e envidar esforços em prol das gerações futuras? Porque, em um dado contexto, as pessoas reconhecem e assumem - pelas mais diversas razões - que alguns sacrifícios em prol do futuro são bons. Não há necessidade de uma referência moral a priori para justificar tal atitude. Existem, por exemplo, boas razões utilitárias para limitar a emissão de gases do "efeito estufa", e, ao procederem dessa forma, o que está sendo desejado, verdadeiramente, é a busca de melhor qualidade de vida, nada mais, e não, necessariamente, as razões utilitárias em si (SINGER, 2004, p. 54).

Há de se reconhecer a força inaudita dos interesses próprios. Até mesmo certas formas de cooperação que surgem numa equipe - como leoas que caçam juntas - podem ter uma motivação egoísta de sobrevivência. O altruísmo desinteressado é algo a ser debatido com mais cuidado (DEMO, 2005, p. 30-33).

Uma outra resistência a Jonas é o fato de que, ao escolher a tese da "heurística do medo", não apenas ele, mas certas igrejas, alguns jornalistas e pesquisadores com forte presença na mídia, têm reivindicado uma ética, que, a partir de certos interditos, o homem tenha sua capacidade de ação limitada para que não se torne uma maldição para si mesmo, para o planeta e para as gerações futuras. É, obviamente, uma ética que encoraja a responsabilidade, mas também é uma ética de conservação, preservação, restrição e impedimento. É de recear-se, portanto, que esta posição venha acompanhada, como a de muitos fundamentalistas, de uma negação à ciência e do conhecimento objetivo em geral, da satanização da técnica e obstaculização dos progressos das ciências, particularmente da biologia e da medicina, indispensáveis para a sobrevivência e o bem-estar da humanidade (CHANGEUX, 1999, p.16).

${ }^{10}$ É um termo cunhado na década de 1900 por George Moore para combater a concepção "naturalista da moral". A "falácia naturalista" consiste na tendência de recorrer-se à "natureza" para explicar e legitimar fatos que estão atrelados ao mundo dos valores e das idéias. Antes de Moore, ainda no século XVIII, David Hume teria criticado o modo pelo qual o que pertence ao domínio do 'dever ser' é derivado do que pertence ao domínio do "ser", deixando em aberto a questão sobre a própria possibilidade de uma derivação desse tipo, pois tudo aquilo que pretende passar de um é para um deve ser, é uma tentativa de deduzir uma conclusão que inclua algo não contido na premissa (um deve ser de um é), o que, sob o ponto de vista lógico é ilegítimo (VAZQUEZ, 1995, p.220). 
Outra crítica, bastante sagaz, é a que Karl-Otto Apel (1987) faz a Jonas. Embora concorde com a proposta de uma ética de responsabilidade para com o futuro, Apel considera que essa ética não pode ser messiânica, que acene para um homem novo, livre de sua ambiguidade aberta para o bem e para o mal, e, sim, que deve ser organizada coletivamente, com a institucionalização em discursos práticos das responsabilidades, em face de um futuro marcado, cada vez mais, pela ciência e tecnologia.

\section{A contribuição de Hans Jonas}

O poder tecnológico à disposição do ser humano é capaz de afetar a natureza e a qualidade de vida das gerações presentes e futuras, e se configura como um fator de risco grave e, historicamente, inusitado, o que obriga, certamente, que seja revisto o conceito de responsabilidade. Nesse ponto, qualquer fórum que se proponha a discutir a problemática ambiental deve considerar esse alto fator de periculosidade e risco. Os princípios propostos por Hans Jonas (heurística do temor e o imperativo da responsabilidade) podem ser elementos orientadores para as decisões a serem tomadas pelos grupos que discutem a problemática ambiental.

Zsolnai (2007, p.10), por exemplo, defende a incorporação dos princípios gerais da ética de Hans Jonas como parte dos sistemas de referências para as decisões sensatas relacionadas ao meio ambiente e no cuidado para com as gerações futuras. Ele postula que as formulações de Hans Jonas podem ser utilizadas como princípios orientadores. Para ele, nenhuma outra teoria trouxe princípios tão claros como a proposta de Jonas. Mas, são princípios que podem ser incluídos numa fórmula, ou matriz de decisão moral, e nunca adotados a priori e descontextualizados.

Hugo Fjelsted Alrøe (2000), na busca de uma perspectiva sistêmica para a ética de responsabilidade, é outro autor que defende a inclusão dos princípios trazidos à luz por Hans Jonas, como elementos de orientação a serem considerados nas decisões éticas em um contexto amplo e sistêmico.

Retornando a Ulrich Beck (apud ACSLELRAD, 2004, p.29-42), nas Sociedades de Risco, há momentos em que os riscos se desconectam dos fundamentos da calculabilidade do seguro que, para ele, são elementos típicos das sociedades industriais do século XX. Nessa perspectiva, a crise ecológica contemporânea resulta do fracasso das instituições responsáveis pelo controle e segurança em administrar riscos incontroláveis. Assim sendo, as medidas de prevenção devem ajustar-se a critérios de precaução, até que se tenha conhecimento científico disponível para lidar com as novas tecnologias.

As situações de riscos que envolvam um forte impacto social ou ambiental devem ser tratadas em uma condição que exija o máximo de bases razoáveis para se crer que não implicam efeitos negativos. Como ocorrem em um contexto de incertezas, visto que os efeitos da ação tecnológica são, em muitos casos, de difícil previsibilidade, torna-se necessária a adoção de princípios conservadores que levem em consideração todos esses aspectos. Dois pontos merecem destaque:

1. Muitas vezes é impossível - em face dos conhecimentos científicos disponíveis - prever os perigos advindos da criação de um produto e (ou) processo. Nesse contexto, as decisões são feitas sempre em função dos conhecimentos do momento, o que as torna virtualmente arriscadas;

2. As responsabilidades dos desenvolvedores de novas tecnologias devem se estender aos domínios ulteriores (e que ainda não são previsíveis). É uma perspectiva preocupante, pois remete as inovações a um domínio espaço-temporal fora da previsibilidade usual.

As circunstâncias exigem, portanto, uma interpretação forte do princípio da precaução, tal como previsto na heurística do medo de Hans Jonas, na qual a prudência e a responsabilidade assumem papel importantíssimo nas tomadas de decisão e na orientação das ações tecnológicas. Por exemplo, as consequências em longo prazo de plantas e animais geneticamente modificados, para a saúde humana e para o equilíbrio ecológico, são manifestações ainda incertas, ou seja, um resultado desastroso pode parecer improvável, mas não existe nada que garanta que seja impossível (REES, 2005, p.129).

É um caso típico em que a heurística do temor de Hans Jonas pode ser utilizada como sendo um substrato para a prudência nas decisões a serem tomadas. Uma prudência que considere a existência do acaso, da incerteza, do risco, do desconhecido, que são componentes da aventura científica em que a modernidade está imersa. É ela que concede certa previsibilidade ao futuro, tão necessária na discussão sobre 
os resultados inesperados da ciência e da tecnologia. Dessa forma, para que se evitem futuros desastres, é melhor, sempre, optar pela opção mais pessimista.

Diante do exposto, pode-se concluir que, a despeito de todas as dificuldades que a ética da responsabilidade de Hans Jonas apresenta no plano teórico, em um horizonte em que até mesmo as ações bem intencionadas podem resultar em consequências dramáticas para seus destinatários, suas formulações são preciosas, pois abordam sistematicamente a problemática que não tem sido tradicionalmente trabalhada pelos filósofos que se dedicam às questões sobre a moral, a conduta humana diante dos imensos desafios oriundos do avanço da tecnologia e da ciência moderna.

\section{Considerações finais}

Theodor Adorno (2000, p.155-156) já havia denunciado o estado de barbárie em que as sociedades ocidentais estão mergulhadas - como sendo aquela situação em que, mesmo estando em seu mais alto desenvolvimento tecnológico, as pessoas se encontram atrasadas em relação à própria civilização, tomadas por uma agressividade primitiva, um ódio primitivo ou, mais apropriadamente, um impulso de destruição, o que contribui para aumentar ainda mais o perigo de que essa mesma civilização venha a explodir, aliás, uma tendência imanente que a caracteriza.

É nesse contexto que a ética de Hans Jonas apresenta seu maior mérito, que foi, sem dúvida, ter colocado a tecnologia como problema filosófico. É difícil discordar de que, em face das terríveis intervenções do homem sobre a natureza, exigem-se agora respostas não só de natureza técnica, mas também ética. Discute-se muito, hoje em dia, que o sucesso do desenvolvimento tecnológico deixou de ser uma fonte de liberação do ser humano e, em certos aspectos, se transformou em uma maldição. O imenso e sempre presente debate sobre a crise ambiental representa a tomada de consciência sobre este fenômeno. Em oposição ao projeto de se enfrentar, de forma exclusivamente com meios técnicos, essa importante questão, o projeto de uma ética para a civilização tecnológica representa, indubitavelmente, uma alternativa decisiva.

O fato de ter trazido a tecnologia para o campo das discussões éticas, particularmente nas éticas aplicadas, foi uma grande realização que não pode ser subestimada.
Hans Jonas fez a mais incisiva argumentação no sentido de colocar a tecnologia como um assunto de capital interesse para a ética. Diferentemente da política ou da religião, por exemplo, a tecnologia sempre foi tratada como algo sem significado moral, um aspecto marginal da vida humana. E foi Hans Jonas quem, definitivamente, fez mudar essa perspectiva.

É inegável que, no campo da ética aplicada, sua contribuição é inestimável. A Heurística do Medo, apresentada por Jonas, deu origem ao amplamente aceito "Princípio da Precaução", da mesma forma que seu imperativo geral, que prevê o cuidado com as gerações futuras, é a base filosófica do chamado "Desenvolvimento Sustentável".

No campo da ética aplicada, em seu livro Técnica, medicina e ética, Jonas abre caminhos para as mais diversas discussões no campo da bioética, da medicina, (a eutanásia e a clonagem humana), dentre outros. São considerações de forte caráter heurístico e que têm inspirado debates sobre esses assuntos tão polêmicos.

Ao procurar uma nova perspectiva ética, uma doutrina que tivesse, em seu cerne, princípios de responsabilidade pública, Hans Jonas estava respondendo a um anseio, às necessidades comuns e condições históricas que acompanham a crise ambiental global; talvez, por isso, seus escritos tenham sido tão bem recebidos por muitos segmentos ambientalistas.

No entanto, como bem comentou Paul Ricoeur (apud ost, 1997, p.329), a ética do porvir apela a uma responsabilidade coletiva, sob forma de "missão que se assume", o que é muito diferente de endossar um princípio de responsabilidade estabelecido como um imperativo $a$ priori, como preconizou Hans Jonas. A primeira alternativa representa uma postura dialogada, enquanto a segunda é um imperativo questionável, o que coloca em xeque a força de sua argumentação.

$\mathrm{O}$ autor do presente artigo defende que uma ética com o perfil proposto por Jonas poderá lograr sucesso, a partir de um discurso aberto e crítico; nunca em bases ontológicometafísicas. Não são os propósitos da vida, "inscritos" no homem que o impelem em direção de uma responsabilidade, mas sim uma motivação (a crise ambiental, por exemplo) que o faz introduzir a necessidade da responsabilidade para com o futuro, no debate das questões éticas. 


\section{Referências}

ABBAGnAnO, N. Dicionário de filosofia, 2.ed. São Paulo: Martins Fontes, 1998.

ACSLELRAD, H. Movimiento de justicia ambiental. In: RIECHMANN, J. (Coord.). Ética ecológica: propuestas para una reorientación. Montevideo: Editorial Nordan-Comunidad, 2004.

ADORNO, T. W. Educação e emancipação. 2. ed. Rio de Janeiro: Paz e Terra, 2000.

ALENCASTRO, M. S. C. A ética de Hans Jonas: alcances e limites sob uma perspectiva pluralista. Tese (Doutorado em Meio Ambiente e Desenvolvimento) - UFPR, 2007. Disponível em: <http://www.dspace.c3sl.ufpr.br/dspace/bitstream/1884/ 10282/1/tese made\%5Bufpr\%5D alencastro_130607.pdf $>$. Acesso em: maio 2009.

ALRØE, H. F. The ethics of responsible acting: a systemic perspective. Ontario: Brock University, 2000. Disponível em: $<$ http://www.orgprints.org/9152/>. Acesso em: jan. 2007.

APEL, K. O. The problem of a macroethic of responsibility to the future in the crisis of technological civilization: an attempt to come to terms with H. Jonas' Principle of responsibility. Man and World, v. 20, n. 1, 1987. 1994.

Estudos de moral moderna. Petrópolis: Vozes,

BECK, U. Risk Society: towards a new modernity. Great Britain: Sage Publications, 1992.

BOURDIEU, P. Escritos de Educação. Petrópolis: Vozes, 1998.

CHANGEUX, J-P. O debate ético em uma sociedade pluralista. In: CHANGEUX, J-P. (Org.). Uma ética para quantos? Bauru, SP: EDUSC, 1999.

DEMO, P. Éticas multiculturais: sobre convivência humana possível. Petrópolis: Vozes, 2005.

DESCARTES, R. Discurso do método. São Paulo: Martins Fontes, 1996.

GIACÓIA J. R. O. Hans Jonas: o princípio responsabilidade. In: OLIVEIRA, M. A. (Org.). Correntes fundamentais da ética contemporânea. Petrópolis: Vozes, 2000.

HABERMAS, J. Técnica e ciência como "ideologia". Lisboa: Edições 70, 1993.
. A ética da discussão e a questão da verdade. São Paulo: Martins Fontes, 2004.

HEIDEGGER, M. A questão da técnica. In: Cadernos de Tradução, n. 2, São Paulo: USP, 1997.

A questão da técnica. In: Ensaios e conferências. Petrópolis, RJ: Vozes, 2002.

Que é isto, a filosofia?: Identidade e diferença. Petrópolis: Vozes; São Paulo: Duas Cidades, 2006.

JAPIASSÚ, H.; MARCONDES, D. Dicionário de filosofia. 2. ed. Rio de Janeiro: Jorge Zahar, 1991.

JONAS, H. Ética, medicina e técnica. Lisboa: Vega Passagens, 1994.

1998.

. Pour une éthique du futur. Paris: Payot \& Rivarges,

. O princípio da vida: fundamentos para uma biologia filosófica. Petrópolis: Vozes, 2004.

O princípio responsabilidade: ensaio de uma ética para a civilização tecnológica. Rio de Janeiro: Contraponto; Ed. PUC-Rio, 2006.

KANT, I. Fundamentação da metafísica dos costumes. In: Os pensadores. 2. ed. São Paulo: Abril Cultural, 1984.

LADRIÈRE, J. Prefácio. In: DUBREUIL, B. H. Imaginário técnico e ética social: ensaios sobre o ofício de engenheiro. Lisboa: Instituto Piaget, s.d.

LIPOVETSKY, G. A sociedade pós-moralista: o crepúsculo do dever e a ética indolor dos novos tempos democráticos. Barueri, SP: Manole, 2005.

MONDELLO, G. Le principe de précaution et industrie. Paris: L'Harmattan, 1998.

OST, F. A natureza à margen da lei: a ecologia à prova do directo. Lisboa: Instituto Piaget, 1997.

REALE, G.; ANTISERI, D. História da filosofia: do romantismo até nossos dias. São Paulo: Paulus, 1991.

REES, M. Hora final - Alerta de um Cientista: o desastre ambiental ameaça o futuro da humanidade. São Paulo: Companhia das Letras, 2005.

RICOEUR, P. The concept of responsibility: an essay in semantic analysis. Chicago: The University of Chicago Press, 2000 . 
RÖPCKE, D.; DAVID, C. G. A. Hans Jonas et les antionmies de l'écologia politique. Écologie \& Politique, v. 29, 2004.

SINGER, P. Um só mundo: a ética da globalização. São Paulo: Martins Fontes, 2004.

VÁZQUEZ, A. S. Ética. 15. ed. Rio de Janeiro: Civilização Brasileira, 1995.
ZSOLNAI, L. Plurality of Values in environmental decision Making, 2007. Disponível em: <http://www.ethics.bkae.hu/ $\mathrm{html} /$ documents/Oxfordworkingpaper.doc $>$. Acesso em: fev. 2007.

Recebido em 3 de maio de 2009.

Aceito em 9 de julho de 2009.

Publicado em dezembro de 2009. 